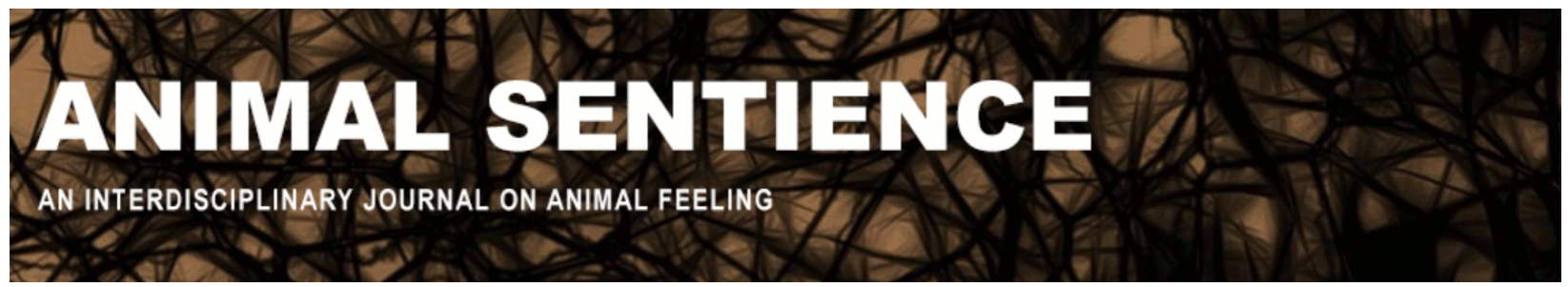

Correia Caeiro, Cátia (2017) Animal and human emotion: Concepts and methodologies. Animal Sentience 14(11)

DOI: $10.51291 / 2377-7478.1252$

Date of submission: 2017-11-13

Date of acceptance: $2017-11-30$

(c)

This article has appeared in the journal Animal

Sentience, a peer-reviewed journal on animal

cognition and feeling. It has been made open access,

free for all, by WellBeing International and deposited

in the WBI Studies Repository. For more information,

please contact

wbisr-info@wellbeingintl.org.

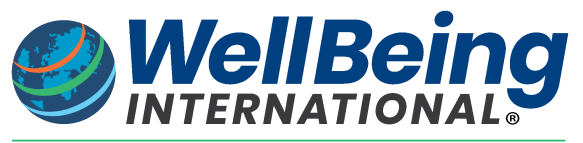

SOLUTIONS FOR PEOPLE, ANIMALS AND ENVIRONMENT 


\title{
Animal and human emotion: Concepts and methodologies
}

\author{
Commentary on Kujala on Canine Emotions
}

\author{
Cátia Correia Caeiro \\ School of Psychology, School of Life Sciences \\ University of Lincoln
}

\begin{abstract}
The human-dog relationship is particularly interesting for the study of emotions. The underlying concepts need to be made explicit and methods need to be adapted to the characteristics of the species studied as well as the shortcomings of the human experimenter's perception.
\end{abstract}

\begin{abstract}
Cátia Correia Caeiro studies the cognitive capacities of different species (e.g., primates and domestic animals), applying a comparative and evolutionary perspective. Her research focuses on communication and emotional expression in animals.

staff.lincoln.ac.uk/881604
\end{abstract}

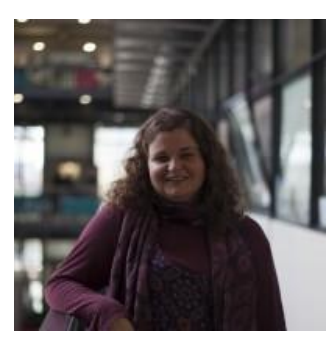

The human brain interprets emotional cues holistically, in a hardwired way, and seems to have evolved an area specialized in reading human faces (Bruce \& Young, 2012; Kanwisher, McDermott, \& Chun, 1997). The Fusiform Face Area probably evolved to allow humans to be experts in specific tasks related to social interaction, but as a consequence it might have created a trade-off where humans lack the capacity to read other species' emotions spontaneously - that is, without extensive training or previous experience - either because the signals are very different or because other factors might affect their perception (e.g., facial morphology, context). When it comes to the human-dog dyad, conceptual and methodological problems frequently arise in the scientific literature. I will address two of them.

1. Concepts and framework. Although there are suggestions that emotions existed much earlier in animal phylogeny than previously assumed (e.g., in fish: Cerqueira et al., 2017; Rey et al., 2015; Vargas, López, \& Portavella, 2012), it is important to be cautious not only about which emotions we are talking about, but also about how these are classified, qualitatively and quantitatively. Researchers should always describe how emotions are being defined, for example, whether the work is based on physiological parameters, brain activation patterns, behavioral expression, or a combination of these. For some species, the words "proto-emotions" or "emotion precursors" might be more appropriate. For example, it is known that cephalopods experience pain, stress, and suffering (Sykes, Baptista, Gonçalves, \& Andrade, 2012), but is this comparable to experiencing happiness, fear, frustration, etc.? Are we talking about the same biological and evolutionary mechanisms? All species might not experience the same kinds of emotions. 
Another consideration is that experiencing, expressing and perceiving emotion all involve different mechanisms, rooted in distinct brain pathways, and they can occur independently: They can be correlated and in some cases causally related (e.g., in humans: Niedenthal, 2007), but not always (e.g., social display rules, such as in a non-Duchenne smile, where a greeting facial expression is displayed without any underlying emotional meaning: Schmidt \& Cohn, 2001). Humans use faces as an important source of emotional and communicative information; this might pose a problem in interpreting other species. Many species seem to present cues throughout the face and body, more so than humans, whose communication cues are displayed mainly by the face. Some domestic animals, for example, make prominent use of their ears (e.g., sheep, horses: Boissy et al., 2011; Hintze, Smith, Patt, Bachmann, \& Würbel, 2016) or tail (dogs: Quaranta, Siniscalchi, \& Vallortigara, 2007) when faced with environmental stimuli that evoke emotional responses. Humans may not be attentive or able to process these cues when our brains are not experienced or hardwired to do it.

2. Methodology. Applying a comparative evolutionary perspective to "human-nonhuman" relationships can be informative about both species. Researchers have been using the human example as a reference point not only because it has been studied much more, but because it can provide clues to how evolution works. Species-specific characteristics need to be taken into account, however, to avoid biases. As Kujala (2017) notes, animal-adapted FACS (Facial Action Coding Systems) and eye-tracking equipment are recent methods already producing promising results. The selection of appropriate tools (i.e., methods) is central to experimental design, but more important is the reasoning behind what tools are being used and why (i.e., methodology). These two concepts are often not considered in this area of study. For example, to ensure functional equivalence in testing different species, one might need to use protocols adapted for each species. While a participant voucher might be enough to motivate a human to perform a task, a piece of food will probably be needed for most dogs.

We do not need to know how dogs feel in order to study how they express their emotions or read emotions in others; nor do we need to know exactly how the brain works in order to study its inputs (e.g., environmental triggers, sensory inputs, etc.) and outputs (e.g., behavior, physiology, etc.). New technology (e.g., fMRI: Berns, Brooks, \& Spivak, 2015) and new methods (eye-trackers, physiological monitors, thermal cameras, FACS, among other instruments) provide non-invasive and unbiased measures to test predictions about what goes on inside the "black box" in both humans and other species (Slater, 1999).

3. Future directions. Addressing Kujala's question about the universality of facial expressions in dogs will need much time and effort. A recent study indicates that facial expressions of emotion are very different for humans and dogs (Caeiro, Guo, \& Mills, 2017). If canine facial expressions are very different from human ones even though the facial musculature is homologous, how do the two species interpret one another's cues? Kujala's target article comes at a pertinent time for progress and discussion. In the next few years, we are likely to see an explosion of empirical studies, debates and conferences on this topic (Ferrari \& de Waal, 2016). 


\section{References}

Andics, A., Gácsi, M., Faragó, T., Kis, A., \& Miklósi, Á. (2014). Voice-sensitive regions in the dog and human brain are revealed by comparative fMRI. Current Biology, 24(5), 574-578.

Berns, G. S., Brooks, A. M., \& Spivak, M. (2015). Scent of the familiar: An fMRI study of canine brain responses to familiar and unfamiliar human and dog odors. Behavioural Processes, 110, 37-46.

Boissy, A., Aubert, A., Désiré, L., Greiveldinger, L., Delval, E., \& Veissier, I. (2011). Cognitive sciences to relate ear postures to emotions in sheep. Animal Welfare, 20(1), 47.

Bruce, V., \& Young, A. W. (2012). Face perception. New York: Psychology Press.

Caeiro, C. C., Guo, K., \& Mills, D. S. (2017). Dogs and humans respond to emotionally competent stimuli by producing different facial actions. Scientific Reports.

Cerqueira, M., Millot, S., Castanheira, M. F., Félix, A. S., Silva, T., Oliveira, G. A., ... Oliveira, R. F. (2017). Cognitive appraisal of environmental stimuli induces emotion-like states in fish. Scientific Reports, 7(1).

Ferrari, P. F., \& de Waal, F. B. M. (2016). Presented at Animal and Human Emotions meeting, Erice, Sicily, Italy.

Hintze, S., Smith, S., Patt, A., Bachmann, I., \& Würbel, H. (2016). Are eyes a mirror of the soul? What eye wrinkles reveal about a horse's emotional state. PLOS ONE, 11(10), e0164017.

Kanwisher, N., McDermott, J., \& Chun, M. M. (1997). The fusiform face area: A module in human extrastriate cortex specialized for face perception. Journal of Neuroscience, 17(11), 4302-4311.

Kujala, M. V. (2017). Canine emotions as seen through human social cognition. Animal Sentience 14(1).

Niedenthal, P. M. (2007). Embodying emotion. Science, 316(5827), 1002-1005.

Quaranta, A., Siniscalchi, M., \& Vallortigara, G. (2007). Asymmetric tail-wagging responses by dogs to different emotive stimuli. Current Biology, 17(6), R199-R201.

Racca, A., Guo, K., Meints, K., \& Mills, D. S. (2012). Reading Faces: Differential lateral gaze bias in processing canine and human facial Expressions in dogs and 4-year-old children. PLOS ONE, 7(4), e36076.

Rey, S., Huntingford, F. A., Boltaña, S., Vargas, R., Knowles, T. G., \& Mackenzie, S. (2015). Fish can show emotional fever: stress-induced hyperthermia in zebrafish. Proceedings of the Royal Society B: Biological Sciences, 282(1819), 20152266.

Schmidt, K. L., \& Cohn, J. F. (2001). Dynamics of facial expression: Normative characteristics and individual differences (pp. 547-550). Presented at the IEEE International Conference on Multimedia and Expo (ICME), IEEE.

Slater, P. J. B. (1999). Essentials of Animal Behaviour. Cambridge University Press.

Sykes, A. V., Baptista, F. D., Gonçalves, R. A., \& Andrade, J. P. (2012). Directive 2010/63/EU on animal welfare: A review on the existing scientific knowledge and implications in cephalopod aquaculture research: Cephalopod aquaculture research welfare. Reviews in Aquaculture, 4(3), 142-162.

Topal, J., Miklósi, Á., Gácsi, M., Dóka, A., Pongrácz, P., Kubinyi, E., ... Csányi, V. (2009). The dog as a model for understanding human social behavior. In M. Naguib, J. Podos, L. Simmons, L. Barret, S. Healy, \& M. Zuk (Eds.), Advances in the Study of Behavior (Vol. 39, pp. 71-116). Elsevier.

Vargas, J., López, J., \& Portavella, M. (2012). Amygdala and emotional learning in vertebrates - A comparative perspective. In B. Ferry (Ed.), The amygdala - A discrete multitasking manager (pp. 1-32). InTech. 